\title{
A interdisciplinaridade na sua interface com o mundo do trabalho
}

\author{
Fernanda Nunes da Rosa Mangini \\ Universidade Federal de Santa Catarina (UFSC)
}

\author{
Regina Célia Tamaso Mioto \\ Universidade Federal de Santa Catarina (UFSC)
}

\begin{abstract}
A interdisciplinaridade na sua interface com o mundo do trabalho
Resumo: Verifica-se que as pesquisas formais sobre interdisciplinaridade, no contexto sócio-histórico de sua evolução, envolveram, além de intelectuais, o investimento do setor econômico. A presente proposta ${ }^{1}$ procura identificar o momento histórico em que a interdisciplinaridade e o mundo do trabalho se aproximam, sinalizando para as possíveis implicações desse encontro. Nessa perspectiva, este artigo focaliza a interface da interdisciplinaridade com o mundo do trabalho e a importância que a referida categoria passa a adquirir nesse espaço. Para tanto, apresenta-se, inicialmente, um breve panorama teórico e histórico da construção e da difusão do conceito de interdisciplinaridade. Após esse percurso, procura-se evidenciar os mecanismos de construção e difusão desse conceito no mundo da produção. O recurso metodológico empreendido foi a pesquisa teórica.
\end{abstract}

Palavras-chave: interdisciplinaridade, conhecimento, trabalho.

\section{Interdisciplinarity in its Interface with the World of Labor}

Abstract: Formal studies about interdisciplinarity in the socio-historic context of their evolution, involve, in addition to intellectuals, investments from the economic sector. This paper uses theoretical research to identify the historic moment at which interdisciplinarity and the world of labor came together, indicating possible implications of this encounter. From this perspective, this article focuses on the interface of interdisciplinarity with the world of labor and the importance that this category acquires in this space. To do so, it initially presents a brief theoretical and historical overview of the construction and diffusion of the concept of interdisciplinarity. It then analyzes the mechanisms of this construction and the diffusion of this concept in the world of production.

Key words: interdisciplinarity, knowledge, labor. 


\section{Apresentação}

A interdisciplinaridade, a partir do final dos anos 1960 , torna-se objeto de pesquisa, mobilizando inúmeros intelectuais e empresários. Desde então, essa categoria passa a ser fortemente veiculada dentro e fora dos espaços acadêmicos como um empreendimento absolutamente necessário, não apenas na esfera do conhecimento, mas também na do trabalho, considerando o contexto de mudanças nos paradigmas do mundo da produção. Porém, estranhamente, muitos debates vinculados à interdisciplinaridade propagam-se aparentemente livres ou independentes de divergências teórico-metodológicas adaptando-se, ao conjunto de transformações em curso no mundo do trabalho e conferindo-lhes legitimidade. Num contexto em que se assiste a uma aproximação cada vez maior entre conhecimento e produção, a interdisciplinaridade, no seu status de categoria do conhecimento, torna-se fundamental por configurar um discurso generalizante, que respalda conjuntos de valores e de práticas em desenvolvimento no mundo do trabalho. É a sua abrangência conceitual, o seu caráter instrumental e a adesão consensual sobre a sua importância que possibilitam o trânsito dessa categoria para além dos espaços acadêmicos.

Nessa perspectiva, pretende-se discutir a categoria interdisciplinaridade ancorada em estudos que buscam compreender o lugar e o papel do conhecimento na sociedade contemporânea. A proposta se fundamenta na necessidade de resgatar a materialidade histórica das mediações da categoria aparentemente exclusiva do mundo do conhecimento com o mundo do trabalho, visando compreender suas relações a partir da dinâmica da sociedade e dos movimentos de sujeitos políticos. Tendo em vista a complexidade da temática, o trabalho é estruturado em três partes. Na primeira são apresentados os fundamentos do conceito de interdisciplinaridade, partindo do marco histórico de construção e difusão conceitual. Aliado a esse marco, na segunda parte está situado o contexto sócio-histórico de desenvolvimento das pesquisas formais sobre a interdisciplinaridade. Ainda nessa segunda parte são resgatadas as primeiras mediações dessa categoria em emergência no mundo do conhecimento com o mundo da produção. Após esse percurso, essas mediações são colocadas em estreita relação com o mundo do trabalho.

\section{$1 \mathrm{Um}$ breve panorama sobre a construção e a difusão do conceito de interdisciplinaridade}

A interdisciplinaridade aparece como alternativa explicitamente inovadora num momento de crítica e oposição aos desdobramentos de uma cultura decor- rente da formação, consolidação e expansão da ciência moderna. Somente a partir do século 20 é possível identificar o aparecimento do termo e seus correlatos em documentos e registros históricos. A referência para a construção da categoria interdisciplinaridade é o relatório do Centro para a Pesquisa e Inovação do Ensino (CERI $)^{2}$, filiado à Organização para Cooperação e Desenvolvimento Econômico (OCDE). Esse relatório, organizado em dezembro de 1969 com o objetivo de distinguir as estruturas institucionais das universidades e seus programas de estudos, apontou para a falta de uma precisão terminológica, causada, fundamentalmente, pelo preconceito no trato de questões referentes à integração e pelo desconhecimento de certos pressupostos básicos relacionados à interdisciplinaridade. Em vista da necessidade de esclarecer esses problemas de terminologia, Guy Michaud foi convocado pelo CERI e, a partir de então, teve início uma reflexão epistemológica que estabeleceu terminologias diferenciadas em quatro níveis: multi (disciplinar), pluri (disciplinar), inter (disciplinar) e trans (disciplinar) (JAPIASSU, 1976).

De acordo com Japiassu (1976), no evento que veio a ser convencionado Seminário sobre interdisciplinaridade e transdisciplinaridade, ocorrido em fevereiro de 1970, reuniram-se 21 representantes de países membros da OCDE, integrando um grupo de especialistas, como Heinz Heckhausen, Jean Piaget, Eric Jantsch, Marcel Boisot, Georges Gusdorf, Andre Lichnerowicz, Asa Briggs, Leo Apostel. Os resultados dos estudos desse grupo pautaram a realização e a divulgação do Seminário internacional sobre pluridisciplinaridade e interdisciplinaridade nas universidades, que aconteceu no período de 7 a 12 de setembro em Nice na França. Organizado pelo CERI/OCDE e pelo Ministério da Educação Francês, esse encontro objetivou esclarecer os conceitos de pluri (disciplinaridade), inter (disciplinaridade) e trans (disciplinaridade) à luz de uma reflexão epistemológica. Continuamente, muitas pesquisas e muitos eventos nesse ínterim foram realizados e, diversos deles, contaram com o patrocínio da OCDE e da Unesco.

As contribuições de especialistas como Jantsch, Heckhausen, Piaget, Michaud, nos eventos relacionados, conformaram as bases conceituais da interdisciplinaridade. Contudo, apesar das semelhanças entre alguns grupos de estudiosos não se chegou a uma definição consensual ${ }^{3}$. De modo geral, conceitos como pluridisciplinaridade, transdisciplinaridade, multidisciplinaridade e interdisciplinaridade constituem as bases para a discussão das relações entre as disciplinas. Desdobramentos destes conceitos como, por exemplo, pluridisciplinaridade auxiliar, metadisciplinaridade, interdisciplinaridade estrutural, tanto para compreensão de novas formas de relacionamento entre as disciplinas, quanto para aproximação de uma 
determinada realidade, são bastante recorrentes na literatura especializada.

Paralelamente a esse movimento de formulação de bases conceituais, outros enfoques sobre o conceito de interdisciplinaridade surgiram na tentativa de compreender, explorar e aprofundar a temática. Dentre esses enfoques, destaca-se o de Lenoir e Hasni (2004) que sinaliza a existência de três conceitos ou lógicas de interdisciplinaridade. A primeira, presente na Europa, principalmente na França, entende a interdisciplinaridade como um fim em si mesmo. $\mathrm{Ou}$ seja, a construção do saber interdisciplinar se justifica pelo conhecer, fixando a questão em dimensões epistemológicas dos saberes e na racionalidade científica centrada na busca do significado (saber-conhecer/polo-objeto). Nessa linha, a unificação do saber ocorre no sentido de uma estruturação hierárquica das disciplinas, uma superciência, metateoria ou metadisciplina. A segunda, notadamente norte-americana, cultivada especialmente nos Estados Unidos, trata a interdisciplinaridade como um meio. Para ela, a construção do saber interdisciplinar constitui um recurso para atingir determinado resultado (saberfazer), firmando o debate da interdisciplinaridade em dimensões metodológicas, revelando sua lógica instrumental orientada para a busca da funcionalidade. A terceira, na concepção originária latino-americana, principalmente brasileira, capta a interdisciplinaridade como uma forma de realização humana. Para esta a construção do saber interdisciplinar se justifica pelo crescimento humano e pela capacidade de emancipação (saber-ser/polo-sujeito). Essa fixa a questão da interdisciplinaridade na busca de si, na construção contínua dos indivíduos, orientada por quatro princípios: humildade, expectativa, coerência e audácia, que expressam sua lógica subjetiva, ou melhor, intersubjetiva, introspectiva.

Nesse ínterim, para Etges (1995), existem dois conceitos de interdisciplinaridade equivocados. $\mathrm{O}$ primeiro, denominado de interdisciplinaridade generalizadora ou universalista, toma a interdisciplinaridade como pressuposto para se chegar a um saber universal, absoluto, totalitário através da articulação de elementos comuns aos saberes que culmina na consolidação de um saber único, superior aos conhecimentos das ciências particulares, consideradas fragmentadas e incompletas. Essa concepção tem subjacente a proposição de um método e um modelo teórico comum para todas as ciências, o que seria fatal para algumas delas, como por exemplo, se as ciências sociais utilizassem o método da física. $\mathrm{O}$ segundo, denominado de interdisciplinaridade instrumental, é bastante parecido com a concepção apresentada por Lenoir e Hasni (2004) de interdisciplinaridade como um meio. Nessa concepção, a ciência não passaria de um mero instrumento a serviço de uma razão instrumental. O que está em jogo é a funcionalidade da ciência, sua capacidade de articular fins e meios. $\mathrm{O}$ conhecimento em si não interessa, apenas o conhecimento mobilizado para resolver problemas. Essa concepção aparece com bastante relevo mais adiante.

Além desses conceitos, outro enfoque na temática da interdisciplinaridade surge a partir do debate dos componentes constituintes do termo, que podem ser considerados como referências mais concretas para o tratamento conceitual. Decompondo o termo interdisciplinaridade, Assumpção (1991) encontra no prefixo "inter" o significante de uma posição ou ação intermediária e/ou recíproca; no substantivo "disciplina", a epistéme, ou seja, a organização e a separação de conhecimentos por meio de um regime de ordem imposta, ou livremente consentida; e no sufixo "dade" o sentido da ação, o resultado dela, o modo de ser e a qualidade. A partir dessa decomposição, fica evidente a importância da disciplina quando o assunto é a interdisciplinaridade. A disciplina tornase então parte integrante do conceito de interdisciplinaridade, uma vez que a abrangência de seus significados pode justificar a conformação dos diferentes conceitos de interdisciplinaridade que coexistem na literatura especializada. Nesse sentido, Pombo (2005) sugere que o debate se paute na etimologia, ou seja, nos diferentes prefixos dos conceitos congêneres de interdisciplinaridade. Assim, na "multi" e na "pluri", a ideia é a mesma, isto é, juntar disciplinas, colocálas lado a lado. Já na "inter", a ideia é o estabelecimento de uma ação recíproca e na "trans", o ir além daquilo que é próprio das disciplinas.

Finalmente e concomitante a esse debate de base conceitual, outros autores, como Rosa (2007), começaram a problematizar a temática da interdisciplinaridade afirmando que, essa não pode ser entendida independentemente das matrizes teóricas do pensamento social, pois a sua concepção está fortemente marcada por diferentes visões de mundo, de homem e de conhecimento ${ }^{4}$. Ainda, segundo Rosa (2007), a grande divergência dos diferentes conceitos de interdisciplinaridade está relacionada às diversas teorias e aos matrizes do pensamento que orientam os estudiosos da temática. Nesse sentido, a autora resgata algumas vertentes de discussão da interdisciplinaridade com base nos trabalhos de Almeida (2000), Melo e Almeida (2000) e Porto e Almeida (2002). Esses autores vão colocar a existência de três vertentes de discussão da interdisciplinaridade que enfatizam, cada qual, determinadas características comuns. São elas: a vertente humanista, a vertente da complexidade e a vertente social crítica.

A vertente humanista defende que a realização de um diálogo ecumênico e reflexivo entre as várias áreas do conhecimento necessita de uma mudança de espírito dos sujeitos envolvidos no empreendimento 
interdisciplinar. A vertente da complexidade realiza uma crítica epistemológica à ciência contemporânea e defende diferentes propostas de integração disciplinar, a partir da incorporação da temática da complexidade e da perspectiva sistêmica. A vertente social crítica dirige sua análise para a dimensão histórica e social da produção do conhecimento, consoante com a perspectiva marxista que, postula estar à ciência moderna subordinada à lógica da divisão social e técnico-científica do trabalho no modo de produção capitalista. A interdisciplinaridade se configura, nessa última vertente, como uma necessidade, mas também e, sobretudo, como um problema. Os expoentes dessa vertente, como Jantsch e Bianchetti (1995), Follari (1995), Etges (1995), entre outros, compreendem que, ao tornar-se um empreendimento absolutamente necessário e urgente, a interdisciplinaridade oferece suporte conceitual e consensual para a conformação de um discurso generalizante de cunho ideológico e político, como panaceia para todos os males. Compreendem ainda que, independentemente da amplitude e das diferenças do debate, as ideias veiculadas a respeito da interdisciplinaridade não se limitam ao mundo do conhecimento. Sua abrangência conceitual e consensual facilita que as ideias em torno dela circulem com bastante elasticidade do mundo do conhecimento para outros espaços.

Nesse sentido é que "a interdisciplinaridade impõe-se como um tema de época [...] Todos invocam em seu favor e ninguém se arriscaria a se pronunciar contra ela" (GUSDORF, 1995, p. 7). Por isso, as ideias genericamente veiculadas a respeito da interdisciplinaridade nem sempre são acompanhadas de uma reflexão crítica acerca da utilidade que representam no contexto da sociedade contemporânea. Dessa forma é que o próximo passo consiste em aproximar a interdisciplinaridade e o contexto favorável à sua afirmação.

\section{0 contexto sócio-histórico da construção e da difusão do conceito de interdisciplinaridade}

Como já exposto, o marco inicial das pesquisas formais sobre a interdisciplinaridade é o evento denominado Seminário sobre pluridisciplinaridade e interdisciplinaridade nas universidades, também conhecido como Congresso de Nice, promovido em 1970 na França. Demandado, apoiado, patrocinado e divulgado pela OCDE, esse evento contou com a presença de empresários de vários países e do Ministério da Educação Francês. Isso constitui o primeiro demonstrativo que a interdisciplinaridade foi originada na confluência entre o meio empresarial e o acadêmico, evidenciando que a sua discussão não é apenas uma preocupação conectada ao mundo da ciência e da educação (MUELLER, 2006).
Para compreender o verdadeiro significado dessas questões, torna-se imprescindível reconstruir o que acontecia em outras esferas sociais, quando houve o início dos debates sobre interdisciplinaridade. O contexto sócio-histórico de construção e difusão do conceito de interdisciplinaridade está sistematizado em dois grandes grupos de acontecimentos vinculados, especialmente, ao campo da produção e ao campo científico num movimento tensionado pelas contradições presentes naquele momento histórico. Dessa forma, o surgimento da interdisciplinaridade está associado, tanto aos conflitos que eclodem nas universidades no final dos anos 1960, quanto à crise do próprio sistema do capital na década de 1970.

\subsection{A crise do capital, a ascensão do toyotismo e o trabalhador polivalente}

A crise do sistema do capital dos anos 1970 ocasionada por inúmeros acontecimentos, como, a crise do petróleo, os movimentos de cunho políticocultural de oposição ao modelo taylorista/fordista, o acirramento da competição entre os países, a busca por novas formas de organização, as mudanças tecnológicas e o esgotamento do modelo fordistakeynesiano -, forçou as empresas e as corporações a entrar num período de racionalização, reestruturação e intensificação do controle da produção. Assim, o capital se organiza em bases mundiais, conformando um novo regime de acumulação, caracterizado pela integração dos centros financeiros mundiais, os quais passam a se articular em blocos econômicos. Iniciase o processo de recomposição do capital, conhecido como reestruturação produtiva, nos países de "capitalismo avançado" englobando singularmente os demais países. $\mathrm{O}$ avanço tecnológico, o toyotismo ${ }^{5}$, e as novas técnicas de gestão organizacional passam a integrar o novo modelo de acumulação caracterizado pela flexibilidade, em oposição à rigidez típica do taylorismo/fordismo ${ }^{6}$ (MOTA; AMARAL, 2006).

O toyotismo, considerado como uma filosofia orgânica da produção industrial, incrementa a ideia de flexibilidade do aparato produtivo e da força de trabalho, oferecendo sustentabilidade a três transformações fundamentais para a promoção da reestruturação econômica. Primeiro, a eliminação do desperdício e a implantação da "produção enxuta", ou seja, da produção reduzida ao estritamente necessário (funções, equipamentos e pessoal). Daí a necessidade do just in time, isto é, da rapidez para disponibilizar as provisões ou matérias primas para a industrialização e comercialização. Segundo, a implantação dos círculos de qualidade total, com o objetivo de detectar possíveis defeitos do processo de produção e comercialização, sem correr o risco de aumentar os custos. Os círculos de qualidade constituem-se numa modalidade de organiza- 
ção do trabalho baseada no comprometimento e na colaboração dos trabalhadores, por meio da disposição de suas experiências e de seus conhecimentos para detectar problemas, propor, programar, avaliar e inovar. Terceiro, a formação contínua. Ou seja, a formação profissional centrada na especialização deixou de combinar com a flexibilidade da produção e dos mercados atuais, já que se direcionava a tarefas claramente delimitadas e definidas no taylorismo/fordismo. No toyotismo, a polivalência e a multifuncionalidade são condições básicas para facilitar as inovações, assegurar a produtividade e a rentabilidade. Dessa forma, o trabalho em equipe passa a ser valorizado, contrastando com o trabalho individual do modelo taylorista/fordista ${ }^{7}$ (ANTUNES, 2005; GOUNET, 1999; SANTOMÉ, 1998).

É, a partir dessa breve reconstrução de acontecimentos históricos, que se pode visualizar, em meados da década de 1970, o desenvolvimento das pesquisas formais sobre a interdisciplinaridade no mundo do conhecimento, afinando-se com um momento de mudança de paradigma no mundo da produção.

\subsection{Os movimentos estudantis, a crítica à especialização e a interdisciplinaridade}

Embora a interdisciplinaridade ainda não estivesse formalmente colocada, sua emergência está relacionada às reivindicações dos movimentos estudantis movidos pela insatisfação com as formas de estruturação do ensino no fim dos anos 1960. Nessa época - assim como os movimentos de trabalhadores, da segunda geração do taylorismo/fordismo, contribuíram para a instauração da crise econômica e política do capital, pela oposição aos desdobramentos do modelo taylorista/ fordista, no mundo da produção -, os movimentos estudantis, com suas reivindicações de cunho político e cultural, também contribuíram para a instauração da crise no âmbito das universidades e instituições de ensino, pela mesma oposição aos desdobramentos do modelo taylorista/fordista, porém no mundo do conhecimento (ANTUNES, 2005; FOLLARI, 1995).

Diante de tais movimentos, próximos nas críticas e demandas, as personificações do capital, na figura dos empresários ligados ao setor da economia, perceberam a necessidade imperiosa de mudanças, sob o risco de perderem seu poder social, econômico, político e cultural. No que diz respeito ao movimento de trabalhadores, os empresários captaram que os operários demonstravam não possuir somente força física. Os trabalhadores demonstravam possuir inteligência, iniciativa, criatividade, entre outros atributos. Os empresários notaram que seria ideal colocar essas capacidades a serviço do capital, como alternativa para a crise econômica, ideológica e política nos meados de 1970. Então, os empresários chegaram à conclusão que poderiam multiplicar seus lucros explorando as capacidades cognitivas dos próprios trabalhadores. Características como criatividade e cooperação, a partir desse momento, não seriam mais desprezadas (ANTUNES, 2005).

No que concerne ao movimento estudantil, os empresários visualizaram que os estudantes universitários se tornavam um grave problema por suas reações anticapitalistas, inicialmente na Europa (França, Alemanha e Itália) e, em seguida, na América Latina (México e Argentina). Esses movimentos estudantis reivindicavam um novo estatuto para Universidade e Escola, contrário ao conhecimento que privilegiava o capitalismo epistemológico de certas ciências, à alienação da academia, às questões da cotidianidade, às organizações curriculares, que evidenciavam a excessiva especialização, e a toda e a qualquer proposta de conhecimento que seguisse numa única, restrita e limitada direção. Começaram, então, as mudanças curriculares e orçamentárias, entre outras. Os empresários captaram na ideia de interdisciplinaridade, que brotava do movimento estudantil, um meio potencial para resolver, no âmbito do conhecimento, os problemas da formação excessivamente especializada do presente e do futuro trabalhador. Nessa perspectiva, a interdisciplinaridade poderia ser o meio de vinculação do conhecimento do novo trabalhador multi-habilitado à sua prática no mundo do trabalho (FOLLARI, 1995; SANTOMÉ, 1998).

Dessa maneira é que as demandas dos movimentos de trabalhadores e, também dos movimentos de estudantes foram ressignificadas. O capital consegue se reorganizar, incorporando à sua maneira ou à sua lógica as reivindicações desses sujeitos políticos, pois, a partir do momento que a interdisciplinaridade entra na agenda dos movimentos sociais, inspirando mudanças, ela entra, também, na agenda dos empresários ligados ao setor da economia. $\mathrm{O}$ Congresso de Nice nos anos 1970 fez ressurgir e ganhar força a interdisciplinaridade como resposta 
do capital aos seus próprios problemas de legitimação. Nesse evento, a interdisciplinaridade foi incorporada ao discurso oficial que, no entanto, absorveu seu potencial crítico ${ }^{8}$. Mesmo tomada como uma categoria aparentemente consensual e livre de contradições, é nesse momento que surgem os termos e os conceitos de interdisciplinaridade e seus correlatos (ANTUNES, 2005; FOLLARI, 1995).

\section{A construção e a difusão do conceito de interdisciplinaridade no mundo do trabalho}

A categoria interdisciplinaridade, formalmente demandada pelo mundo da produção por meio da OCDE, tornou-se palavra de ordem nas últimas décadas. O empresariado procurou, e encontrou nela, respaldo teórico precioso para fundamentar e impulsionar a transição do modelo taylorista/fordista para o modelo toyotista de acumulação flexível, considerando que cada modelo de produção e distribuição requer pessoas com determinadas capacidades, conhecimentos, habilidades e valores. No modelo taylorista/fordista, os trabalhadores do chão de fábrica concentravam-se em poucas tarefas simplificadas, isoladas e rotineiras. $\mathrm{O}$ trabalho estava dissociado entre concepção (função de gerentes) e execução (função de operários). Os sinais do taylorismo/ fordismo no mundo do conhecimento consistem basicamente na fragmentação dos processos de produção e difusão do conhecimento, acentuando a divisão entre áreas, departamentos, cursos, currículos, conteúdos etc. No horizonte está a formação em tempo determinado do trabalhador especializado para exercer uma função específica de acordo com a separação entre concepção e execução (ANTUNES, 2005; MUELLER, 2006).

Ao contrário, no modelo toyotista, os trabalhadores são estimulados a aumentar a produtividade, participando e interagindo com a empresa individualmente e/ou em equipes. Assim, os trabalhadores participam em diferentes níveis de concepção e execução (polivalência, multifuncionalidade). Nesse modelo, não se exerce o domínio somente sobre o corpo e a força física dos trabalhadores. É preciso, sobretudo, dominar a subjetividade dos mesmos (seus gostos, preferências, emoções, inteligência, criatividade etc) no intuito de fazer com que eles se identifiquem como parte integrante da empresa (coordenador/colaborador), de modo a perseguirem os objetivos dela na direção do movimento do capital. Por isso, na filosofia do modelo toyotista de acumulação flexível existe a redescoberta da pessoa trabalhadora como elemento-chave da rentabilidade e da competitividade da empresa. Existe um maior aproveitamento do saber e da experiência do trabalhador (ANTUNES, 2005; SANTOMÉ, 1998).
As ideias genericamente veiculadas a respeito da interdisciplinaridade seduzem o trabalhador para o desenvolvimento de uma subjetividade adequada ao novo momento de acumulação de capital. Nessa perspectiva, a interdisciplinaridade é tomada como uma atitude de abertura do sujeito individual ou coletivo (equipe), disposto à: integração, interação, coordenação, colaboração, e à cooperação. Além de disposição e abertura, é fundamental desenvolver uma postura flexível em face das mudanças, das novidades e das diferenças. O sujeito interdisciplinar é um aventureiro que busca ultrapassar as barreiras do conhecimento e inovar, ou seja, ser transdisciplinar. $\mathrm{O}$ apelo à interdisciplinaridade ajuda a inculcar na mente dos trabalhadores que sem cooperação e compromisso é impossível aumentar a produtividade. $\mathrm{O}$ trabalhador precisa desenvolver, com o auxílio da perspectiva interdisciplinar, uma visão do conjunto do processo produtivo para se adaptar às flutuações da produção com flexibilidade, agilidade e eficiência. A interdisciplinaridade seria um meio de estimular a criatividade do trabalhador, sendo ela necessária para conferir personificação aos produtos que, no toyotismo, devem ser fabricados de acordo com as preferências do cliente (ANTUNES, 2005).

Categoria aparentemente exclusiva do mundo do conhecimento, a interdisciplinaridade vai se combinar com um conjunto de valores, práticas e discursos em desenvolvimento no mundo do trabalho. O seu status de categoria do conhecimento confere legitimidade às transformações em curso. Dada a sua abrangência de significados, o seu caráter instrumental e a sua concepção de panaceia, para Mueller (2006, p. 49), a interdisciplinaridade é um conceito que foi "cooptado pelo modo de produção capitalista, e que, em consequência, incorporou o espírito do capitalismo". De acordo com o autor, tanto no mundo do trabalho, quanto no mundo do conhecimento, a interdisciplinaridade é invocada de maneira indiscriminada para a concretização de fins puramente instrumentais. Nesse ideário, o trabalhador deve desenvolver um conjunto de competências ${ }^{9}$ e habilidades que lhe garantam um posto de trabalho. Na lógica das competências, o trabalhador é responsabilizado pelo sucesso ou fracasso de sua trajetória educacional e profissional. Daí que o crescimento do desemprego, por exemplo, justifica-se pela falta de formação, experiência, habilidades e competências do trabalhador. Nesse caso, bastaria criatividade, desejo, iniciativa, espírito empreendedor etc. Com a difusão do conceito de interdisciplinaridade, as exigências de trabalho em equipe, competência, polivalência, multifuncionalidade, desespecialização ganham respaldo acadêmico/científico, ou seja, base teórico-metodológica.

Na medida em que a divisão social do trabalho tende para a indivisão - e, consequentemente, os 
postos de trabalho tendem para a flexibilidade e a instabilidade na distribuição de tarefas -, o trabalho da equipe interdisciplinar é invocado pelo capital. Isso ocorre em nome do exercício da solidariedade mútua, mas, contraditoriamente, constrói-se como um espaço tenso e conflituoso de exercício da competitividade, tendo em vista o aumento da produtividade individual e coletiva. Na concepção de Gounet (1999), o novo modelo de organização da produção exige ainda mais do operário. As exigências valem tanto para os trabalhadores empregados, quanto para aqueles desempregados que desejam ocupar um posto de trabalho. A falta de interdisciplinaridade, associada à noção da falta de formação, experiência, habilidades, qualificações e competências do trabalhador, ajuda a justificar a crise de postos de trabalho. Nessa perspectiva, a interdisciplinaridade confirma a institucionalização de novos modelos de educação e formação para os trabalhadores, além da gestão interna das organizações e do mercado de trabalho em geral, sob novos códigos profissionais.

\section{À guisa de conclusão}

As razões de emergência da interdisciplinaridade, apresentadas por Japiassu (1976), evidenciam a sua instrumentalidade perante o novo momento do sistema capitalista. Ao discorrer sobre um questionário aplicado pela OCDE, intitulado Estudo sobre as atividades interdisciplinares de ensino e de pesquisa nas universidades, traz, como motivos para a busca da interdisciplinaridade: a necessidade de reorientar os estudos sem perda de tempo; a possibilidade de criação de novas carreiras; e a necessidade de melhor adaptação ao emprego. Mais evidente ainda são as inúmeras utilidades da interdisciplinaridade apontadas por Fazenda (1993), com base em estudos realizados por pesquisadores de diferentes universidades dos Estados Unidos, Reino Unido, da França, Alemanha, Turquia e da Áustria para a OCDE. Esses estudos trazem, explicitamente, o contexto muito favorável para a emergência da interdisciplinaridade através das concepções de estudantes e professores, que a apontam como o meio de:

a) conseguir uma melhor formação geral, por permitir que estudantes "aprendam a aprender" e se posicionem diante da sociedade e do mundo, compreendendo e criticando um arsenal de informações;

b) atingir uma formação profissional qualificada, por permitir o aporte de muitas disciplinas fundamentais, considerando as possibilidades futuras de mudança de profissão, em função da mobilidade de emprego e necessidade de polivalência; c) incentivar a formação e o progresso de pesquisadores e de pesquisas por proporcionar diálogo e interação entre disciplinas;

d) possibilitar alternativa de formação permanente, capaz de superar a dicotomia ensino/pesquisa;

e) conhecer, através de diferentes abordagens, as múltiplas e variadas expressões do mundo e modificá-lo.

De acordo com Mueller (2006, p. 38), a interdisciplinaridade no mundo do trabalho atua como um "novo santo" que pode

[...] efetivamente operar os milagres necessários para que os indivíduos permaneçam ou assumam novos postos de trabalho. Esses novos saberes (ou competências) acabam sendo altamente funcionais, em termos de atingir os objetivos/metas propostos no mundo do trabalho. Pelo fato destes terem uma máscara de panaceia (altamente sedutora e fetichizada), a sua assimilação dá-se pelas vias da mais pura e simples adesão, e não de maneira truculenta, imposta, via coerção. Dentro desse universo, a interdisciplinaridade de forma fetichizada, tem atuado muitas vezes como 'lobo em pele de cordeiro'. A sua incorporação no mundo do trabalho tem um objetivo/fim muito claro: ser operacional na obtenção de melhores resultados (de preferência financeiros) no ambiente organizacional por meio da constituição de grupos interdisciplinares (assim denominados), envolvendo vários setores da empresa, e, individualmente, como um suposto favorecimento, onde o acúmulo de funções (multifuncionalidade), por parte dos trabalhadores sobreviventes às reengenharias e 'downsizings', torna-se um aprimoramento ou qualificação, uma forma de agregar novos conhecimentos.

Esses indicativos demonstram a subsunção do mundo do conhecimento ao mundo do trabalho, ao mesmo tempo em que apontam para o presente e o futuro da interdisciplinaridade nesses espaços.

\section{Referências}

ALMEIDA, G. E. S. de. Pra que somar se a gente pode dividir?: abordagens integradoras em saúde, trabalho, meio ambiente. 90f. Dissertação (Mestrado em Saúde Pública) Escola Nacional de Saúde Pública, Fundação Oswaldo Cruz, Rio de Janeiro, 2000.

ANTUNES, R. Os sentidos do trabalho. São Paulo: Boitempo, 2005.

ASSUMPÇÃO, I. Interdisciplinaridade: uma tentativa de compreensão do fenômeno.In: FAZENDA, I. C. A. (Org.). 
Práticas interdisciplinares na escola. São Paulo: Cortez, 1991.p. 23-35.

ETGES, N. J. Ciência, interdisciplinaridade e educação. In: JANTSCH, A. P.; BIANCHETTI, L. (Org.). Interdisciplinaridade: para além da filosofia do sujeito. Petrópolis: Vozes, 1995. p. 51-84.

FAZENDA, I. C. A. Integração e interdisciplinaridade no ensino brasileiro. São Paulo: Loyola, 1993.

FOLLARI, R. A. Interdisciplinaridade e dialética: sobre um mal entendido. In: JANTSCH, A. Paulo; BIANCHETTI, L. (Org.). Interdisciplinaridade: para além da filosofia do sujeito. Petrópolis: Vozes, 1995. p. 127-141.

GOUNET, T. Fordismo e toyotismo na civilização do automóvel. São Paulo: Boitempo, 1999.

GUSDORF, G. Passado, presente, futuro da pesquisa interdisciplinar. Tempo Brasileiro, Rio de Janeiro, n. 121, p. 7-27, abr./jun. 1995.

HARVEY, D. Condição pós-moderna. São Paulo: Loyola. 1989.

JANTSCH, A. P.; BIANCHETTI, L. Universidade e interdisciplinaridade. In: (Org.). Interdisciplinaridade: para além da filosofia do sujeito. Petrópolis: Vozes, 1995. p. 195-203.

JAPIASSU, H. Interdisciplinaridade e patologia do saber. Rio de Janeiro: Imago, 1976.

LENOIR, Y.; HASNI, A. La interdisciplinaridad: por un matrimonio abierto de la razón, de la mano y del corazón. Revista Iberoamericana de Educación, n. 35, p. 167-185, mayo/agosto 2004. Disponível em: <http:/www.rieoei.org/ rie35a09.htm>. Acesso em: 13 ago. 2007.

MELO, A. I. S. C. de; AlmeidA, G. E. S. de. Interdisciplinaridade: possibilidades e desafios para o trabalho profissional. In: Capacitação em Serviço Social e Politica Social: o trabalho do assistente social e as políticas sociais, Brasília: UNB/CEAD, 2000. (v. 4).

MOTA,A. E.;AMARAL, Â. S. do. Reestruturação do capital, fragmentação do trabalho e Serviço Social. In: MOTA, A. E. (Org.). A nova fábrica de consensos: ensaios sobre a reestruturação empresarial, o trabalho e as demandas ao Serviço Social. São Paulo: Cortez, 2006. p. 23-44.

MUELLER, R. R. Trabalho, produção da existência e do conhecimento: o fetichismo do conceito de interdisciplinaridade. 115f. Dissertação (Mestrado em Educação) - Programa de Pós-Graduação em Educação, Universidade Federal de Santa Catarina, Florianópolis, 2006.
PAVIANI, J. Interdisciplinaridade ou uma nova disciplina. Caxias do Sul, 10 p. 1993. Digitado.

POMBO, O. Interdisciplinaridade e integração dos saberes. Liinc em Revista, Rio de Janeiro, v. 1, n. 1, mar. 2005. Disponível em: <http://www.ibict.br/liinc $>$. Acesso em: 4 maio 2007.

PORTO, M. F. de S.; ALMEIDA, G. E. S. de. Significados e limites das estratégias de integração disciplinar: uma reflexão sobre as contribuições da saúde do trabalhador. Ciência e Saúde Coletiva, v. 7, n. 2, 2002. Disponível em: $<$ http://www.Scielosp.org/scielo.php?script $=$ sci arttext\&pid=S141381232002000200013\&lng-pt\&nrm=iso>. Acesso em: 13 ago. 2007.

ROSA, F. N. Interdisciplinaridade: marcos referenciais para o debate no serviço social. 95f. Trabalho de Conclusão de Curso (Graduação em Serviço Social) - Departamento de Serviço Social, Universidade Federal de Santa Catarina, Florianópolis, 2007.

SANTOMÉ, J. T. Globalização e interdisciplinaridade: o currículo integrado. Tradução de Cláudia Schilling. Porto Alegre: Artes Médicas, 1998.

STROOBANTS, M. A visibilidade das competências. In: ROPÉ, F.; TANGUY, L. (Org.). Saberes e competências: o uso de tais noções na escola e na empresa. Campinas: Papirus, 1994. p. 135-167.

\section{Notas}

1 Este artigo foi elaborado a partir da pesquisa denominada " $\mathrm{O}$ processo de construção do espaço profissional do assistente social em contextomultiprofissional: um estudo sobreo Serviço Social na Estratégia Saúde da Família”, que contou com apoio doCNPq. Processonúmero:503063/2004-5.

2 O CERI tem como objetivo encorajar e desenvolver a cooperação entre os países membros da OCDE, no campo da pesquisa e da inovação no ensino.

3 No Brasil,Hilton Japiassu(1976)e Ivani Fazenda(1993) foram pioneiros na divulgação desses conceitos que inspiraram reformulações, adaptações e modificações.

4 De acordo com Ari Jantsch e Bianchetti (1995), a interdisciplinaridade parte de demandas de diferentes naturezas, remetendo a diferentes visões de mundo, de homem e de conhecimento.

5 O toyotismo é um modo de organização da produção capitalista originário do Japão, resultante da conjuntura desfavorável do país. Foi criado na fábrica da Toyota por Taiichi Ohno, após a Segunda Guerra Mundial. Por meio 
desse modelo de produção, as empresas toyotistas conquistaram grande espaço no cenário mundial. A partir de meados da década de 1970, as empresas toyotistas assumiriam a supremacia produtiva e econômica, principalmente pela sua sistemática produtiva que, consistia em produzir bens pequenos, que consumissem pouca energia e matéria-prima, ao contrário do padrão norte-americano (GOUNET, 1999).

6 Otaylorismo/fordismo possibilitou uma autêntica revolução tecnológica e organizativa no mundo da produção e distribuição, mais expressivamente após a Segunda Guerra Mundial até meados da década de 1970. No ideário de tal modelo administrativo e organizacional, os gestores acusavam os trabalhadores do chão de fábrica de "vagabundagem sistemática", justificando medidas "científicas" de controle e fragmentação dos processos de produção em operações elementares, simples e automáticas. Essas medidas dificultavam que esses trabalhadores participassem das decisões e do controle das empresas. Além de acentuar a divisão social e técnica de trabalho, essas medidas contribuíram para a separação entre trabalho intelectual e manual, ou seja, entre aqueles que pensam, ordename aqueles que obedecem, executam(GOUNET, 1999; SANTOMÉ, 1998).

7 Apesar do modelo taylorista/fordista persistir, principalmente nos países periféricos, as características do modelo toyotista no seu todo ou em parte se fazem cada vez mais presentes em diferentes países nos últimos tempos. Uma de suas características mais generalizadas é a cooptação do poder sindical, provocando o enfraquecimento do movimento operário. A ameaça do desemprego e a imposição da competitividade colocam ainda mais obstáculos às reivindicações coletivas. Diferentemente do modelo taylorista/fordista, os trabalhadores são chamados a participar das decisões e do controle de questões diretamente envolvidas a eles nas empresas. No entanto, a delegação do poder ocorre até certos limites, os controles tornam-se difusos, pois as hierarquias do poder são ocultadas (ANTUNES, 2005; GOUNET, 1999).

8 Por outro lado, a interdisciplinaridade se manteve simetricamente como demanda dos setores anticapitalistas, compatibilizando com as exigências dos estudantes, em face da relativa hierarquização no meio acadêmico e profissional, além de outras questões (FOLLARI, 1995). Nesse sentido, a interdisciplinaridade movimenta-se entre projetos societários antagônicos.

9 A noção de competência carece de conceitos e definições consensuais, no entanto, Stroobants (1994), consegue caracterizá-la por tipos de saber, apontando para a sintonia dessa noção com tipos específicos de saber. De maneira geral, o modelo de competências articula a palavra "saber" a uma ação ou a um verbo da ação. Essencialmente, a forma sistemática das competências mobilizadas consiste no trio: saberes, saber-fazer e saber-ser. Pertencem ao registro dos saberes os conhecimentos profissionais de base (informática, contabilidade, expressão oral e escrita). O domínio do saberfazer designa as noções relacionadas à execução prática do trabalho (tarefas, regras, procedimentos, informações, além de saber-agir, saber-transformar). Já o saber-ser diz respeito a qualidades pessoais (ordem, método, precisão, rigor, polidez, autonomia, imaginação, iniciativa, adaptabilidade, comunicação, ambição).

\section{Fernanda Nunes da Rosa Mangini}

fernanda_nunes_rosa@yahoo.com.br Mestranda do Programa de Pós-Graduação em Educação, Universidade Federal de Santa Catarina (UFSC)

Bolsista do Conselho Nacional de Desenvolvimento Científico e Tecnológico (CNPq)

Orientador: Prof. Dr. Ari Paulo Jantsch

Co-orientador: Prof. Dr. Lucídio Bianchetti

\section{Regina Célia Tamaso Mioto}

mioto@cse.ufsc.br

Doutora em Saúde Mental pela Universidade Estadual de Campinas (Unicamp)

Pós-doutorado na Universidade de Perugia-Itália

Professora da Graduação e da Pós-Graduação da UFSC

Bolsista de produtividade em pesquisa do Conselho Nacional de Desenvolvimento Científico e Tecnológico (CNPq)

\section{UFSC}

Programa de Pós-Graduação em Serviço Social Campus Universitário Reitor João David Ferreira Lima

Bairro Trindade

Florianópolis - Santa Catarina - Brasil

CEP: 88010-970 